\title{
Depressive Realism and Outcome Density Bias in Contingency Judgments: The Effect of the Context and Intertrial Interval
}

\author{
Rachel M. Msetfi \\ University of Hertfordshire \\ Jane Simpson \\ University of Lancaster
}

\author{
Robin A. Murphy \\ University College London \\ Diana E. Kornbrot \\ University of Hertfordshire
}

\begin{abstract}
The perception of the effectiveness of instrumental actions is influenced by depressed mood. Depressive realism (DR) is the claim that depressed people are particularly accurate in evaluating instrumentality. In two experiments, the authors tested the DR hypothesis using an action-outcome contingency judgment task. DR effects were a function of intertrial interval length and outcome density, suggesting that depressed mood is accompanied by reduced contextual processing rather than increased judgment accuracy. The DR effect was observed only when participants were exposed to extended periods in which no actions or outcomes occurred. This implies that DR may result from an impairment in contextual processing rather than accurate but negative expectations. Therefore, DR is consistent with a cognitive distortion view of depression.
\end{abstract}

Cognitive theories of depression postulate the existence of a negative self-referent cognitive bias that results in a systematic distortion of reality and, consequently, depressive symptomatology (Beck, 1967). Although considerable evidence supports this view (for detailed reviews, see Coyne \& Gotlib, 1983; Gotlib, Kurtzman, \& Blehar, 1997; Teasdale \& Barnard, 1993; Williams, Watts, MacLeod, \& Mathews, 1997), some research has shown that depression can also lead to more realistic cognitions (e.g., Lewinsohn, Mischel, Chaplin, \& Barton, 1980). The strongest evidence for depressive realism (DR) is argued to come from contingency judgment tasks, as these contain an objective measure of reality with which judgments made by depressed people may be compared (Ackermann \& DeRubeis, 1991; Clark, Beck, \& Alford, 1999; Dobson \& Franche, 1989).

Using this methodology, Alloy and Abramson (1979) found that nondepressed people are more likely than depressed people to think that outcomes are contingent on their actions when they are not. They concluded that in comparison to depressed people, whose perceptions are apparently accurate, nondepressed people distort reality in an optimistic fashion. One interpretation of DR is that nondepressed people possess a positive bias, which allows

Rachel M. Msetfi and Diana E. Kornbrot, Department of Psychology, University of Hertfordshire, Hatfield, Hertfordshire, United Kingdom; Robin A. Murphy, Department of Psychology, University College London, London, United Kingdom; Jane Simpson, Department of Clinical Psychology, Institute for Health Research, University of Lancaster, Lancaster, United Kingdom.

This study was carried out as part of Rachel M. Msetfi's doctoral dissertation.

Correspondence concerning this article should be addressed to Rachel M. Msetfi, Department of Psychology, University of Hertfordshire, Hatfield, Hertfordshire AL10 9AB, United Kingdom. Email: r.m.msetfi@ herts.ac.uk them to feel in control of their environment. Evidence derived from the normal population ${ }^{1}$ appears to support this conclusion, because random samples also exhibit a tendency to overestimate relationships between noncontingent events (Dickinson, Shanks, \& Evenden, 1984), although this is not always the case (e.g., Wasserman, Elek, Chatlosh, \& Baker, 1993).

In the following review of the literature, we describe contingency judgment methodology before reviewing evidence and theoretical explanations for DR in contingency judgment. We then report evidence suggesting that features of experimental tasks that encourage participants to integrate all available information into their judgments are responsible for patterns of bias in nondepressed individuals. We further suggest that DR effects occur because depressed people do not use all the available evidence to arrive at their judgments rather than because they are being realistic. We then report the findings of two experiments that support these hypotheses.

\section{Contingency Judgment}

People who can accurately judge when outcomes are contingent on their actions can control the occurrence of outcomes or discontinue inappropriate behavior. Another type of judgment concerns predicting whether one event is contingent on the occurrence of a preceding event. There is value in the ability to learn both types of relationship. In empirical tasks, both types of judgment involve the experimenter programming a series of response- or eventcontingent outcomes and asking participants to judge the degree to which the response or event predicts or causes the outcome. Judgments can then be compared with the actual degree of contingency by calculating one of several similar contingency metrics

\footnotetext{
${ }^{1}$ Normal population refers to random samples drawn from the normal population in studies where depressed mood was not a variable of interest.
} 
(see Allan, 1980, and Crocker, 1981, for discussions of appropriate measures) that, it is argued, constitute an objective measure of reality (Ackermann \& DeRubeis, 1991).

The response-outcome contingency judgment task used in many DR studies can be summarized as follows. Participants are given multiple opportunities to press (or not press) a button, which sometimes produces an outcome (e.g., light onset), depending on the programmed contingency. If the light switches on more often in the presence of the response than in its absence, participants should learn that they have some control over light onset. There are four possible types of event-outcome conjunctions, which can be summarized in a $2 \times 2$ contingency table (see Table 1 ) and used to calculate a contingency metric $(\Delta P ;$ Allan, 1980). The response-outcome contingency is simply the probability of the outcome given the response $[P(\mathrm{O} / \mathrm{R})]$ minus the probability of the outcome given no response $[P(\mathrm{O} /$ no $\mathrm{R})]$. The different levels of contingency can include no control (zero contingency) or some degree of control (positive contingency) over the outcome (see Table 1). Therefore, $\Delta P$ is one objective measure with which participants' judgments of their degree of control can be compared.

\section{DR in Contingency Judgment Studies}

Early experimental work on contingency judgments suggested that people in general were not accurate estimators of contingency because their judgments deviated from $\Delta P$ (e.g., L. J. Chapman \& Chapman, 1967; Smedslund, 1963). However, Alloy and Abramson (1979) claimed that depression may actually increase accuracy. In one experiment, they exposed participants to one of two conditions, both of which involved a zero contingency between button pressing and light illumination. In other words, pressing the button had no impact on the likelihood of the light switching on. The two conditions differed, however, as to the frequency (density) with which the outcome occurred. In the low- and high-

Table 1

Three Panels Showing $2 \times 2$ Contingency Tables Displaying the Four Possible Combinations of Response-Outcome Information

\begin{tabular}{|c|c|c|}
\hline \multirow[b]{2}{*}{ Response } & \multicolumn{2}{|c|}{ Outcome } \\
\hline & Present & Absent \\
\hline \multicolumn{3}{|c|}{ Generic information } \\
\hline Present & A & B \\
\hline Absent & $\mathrm{C}$ & $\mathrm{D}$ \\
\hline \multicolumn{3}{|c|}{$\Delta P=0$, low outcome density ${ }^{\mathrm{a}}$} \\
\hline Present & 5 & 15 \\
\hline Absent & 5 & 15 \\
\hline \multicolumn{3}{|c|}{$\Delta P=0$, high outcome density ${ }^{\mathrm{b}}$} \\
\hline Present & 15 & 5 \\
\hline Absent & 15 & 5 \\
\hline
\end{tabular}

Note. Contingency $=\Delta P=\mathrm{A} /(\mathrm{A}+\mathrm{B})-\mathrm{C} /(\mathrm{C}+\mathrm{D}) \cdot P(\mathrm{O} / \mathrm{R})=$ conditional probability of the outcome given the presence of the response; $P(\mathrm{O} /$ no $\mathrm{R})=$ conditional probability of the outcome given the absence of the response.

${ }^{\mathrm{a}} P(\mathrm{O} / \mathrm{R})=.25, P(\mathrm{O} / \mathrm{no} \mathrm{R})=.25$.

${ }^{\mathrm{b}} P(\mathrm{O} / \mathrm{R})=.75, P(\mathrm{O} /$ no $\mathrm{R})=.75$. density conditions, the outcome occurred $25 \%$ and $75 \%$ of the time, respectively (see Table 1). If participants were accurate or "realistic," then both conditions should be judged similarly because even though the absolute number of outcomes differed across conditions, the overall contingency remained constant. The results showed that although nondepressed people's judgments of control were higher as the number of outcomes increased, depressed people's judgments were not. This increase in nondepressed people's judgments, which occurs in conditions of high outcome density (OD), has been interpreted as an optimistic bias. The lack of OD bias on the part of depressed participants purportedly reflected their tendency to be more realistic in their perceptions. $^{2}$

The effect has been replicated using different protocols in which responding does not control the outcome (zero contingencies) but the outcome occurs frequently (Alloy, Abramson, \& Kossman, 1985; Benassi \& Mahler, 1985; Martin, Abramson, \& Alloy, 1984; Vasquez, 1987). There is little evidence so far that this is a general difference in contingency learning, because with positive contingencies in which the participant does have control over the outcome, no differences between depressed and nondepressed people have been reported (Alloy et al., 1985; Carson, 2001; Cobbs, Critelli, \& Tang, 1990; Ee, 1994; Lennox, Bedell, Abramson, Raps, \& Foley, 1990; Vasquez, 1987).

A number of theoretical accounts have been advanced to explain why the effect depends on zero contingencies. For example, zero contingencies may fit in with depressed people's expectations of having no control over events, producing the apparently more realistic pattern of judgments (Alloy \& Abramson, 1979). However, nondepressed people are argued to have higher expectations of control in such conditions, and their higher judgments accord with this finding. Additionally, nondepressed people may be motivated to maintain their self-esteem, which is associated with having control over events, producing higher judgments of control in zero contingencies. The suggestion is that this motivation is simply not present in depressed people (Ackermann \& DeRubeis, 1991). Either or both motivational and expectations factors could contribute to the observed DR effect. Furthermore, these explanations for DR concur with evidence of no mood difference when positive contingencies are tested.

However, there is no adequate account explaining why the DR effect only appears in conditions with high OD. There is a suggestion that the frequency of occurrence could influence the outcome's perceived valence (e.g., Alloy \& Abramson, 1979, p. 462), which would subsequently reduce mood differences. The evidence for this view, however, is anecdotal, and it could be argued that

\footnotetext{
${ }^{2}$ Alloy and Abramson's "depressed" participants did not receive a clinical diagnosis of depression. All participants completed the Beck Depression Inventory (BDI; Beck, Ward, Mendelson, Mock, \& Erbaugh, 1961) and were assigned to depressed or nondepressed groups on the basis of criteria proposed by Beck et al. The criteria were such that participants scoring 8 or less on the BDI were categorized as nondepressed, whereas those scoring 9 or above were categorized as mildly depressed. Therefore, Alloy and Abramson's depressed participants might be more correctly described as dysphoric. In this article, for the sake of simplicity, the term depression will be used to indicate dysphoria. Studies using dysphoric participants will be referred to as analogue studies and those using clinically depressed participants will be referred to as clinical studies.
} 
that any similarity between depressed and nondepressed people's judgments in zero contingency conditions remains problematic for purely expectations and motivational accounts of DR.

\section{OD Effects in the Normal Population}

The idea that expectations about specific scenarios determine participants' judgments has not been restricted to the DR literature (Alloy \& Tabachnik, 1984). Random samples of the population show a strong tendency to overestimate high-density contingencies not only in control tasks, sometimes referred to as operant tasks (Dickinson et al., 1984), but also predictive tasks in which participants judge relationships between symptoms and diagnoses (L. J. Chapman \& Chapman, 1967). Alloy and Tabachnik (1984) argued that in both situations, participants have strong a priori expectations that events are associated. Further support for this view comes from a DR study in which predictive contingencies were arranged between appearances of colored shapes on a screen (Alloy et al., 1985). Judgments in this task were argued to be uninfluenced by expectations and no difference was found between depressed and nondepressed people's judgments of a highdensity zero contingency. This was interpreted as support for the theory that judgments are not simply determined by statistical contingency but also by the expectations that participants hold regarding a given experimental situation.

However, we feel that this explanation and expectations-driven theory alone are inadequate to explain OD effects and consequently DR. This is because evidence suggests that task structure also determines whether OD effects occur. The studies mentioned above are similar in that contingency information is presented to participants using discrete trials. Each event-outcome conjunction in the contingency table constitutes one experimental trial. Trials are constructed such that there is a marked period of time in which the response can occur followed by a period in which the outcome can occur. Studies finding evidence of both OD and DR effects have used this type of discrete trials procedure, where each trial is separated from the next by an intertrial interval (ITI).

Of particular relevance to this discussion is evidence from other sequential tasks in which no OD bias was observed. For example, Allan and Jenkins $(1980,1983)$ used an operant discrete trials procedure that did not contain an ITI and found no evidence of OD bias in several experiments. Similarly, Wasserman, Chatlosh, and Neunaber (1983) developed a free-operant procedure without an ITI, where participants were free to make or withhold their responses at any time during the task. To program the contingency, Wasserman et al. segmented the task into unsignaled, 1-s time bins. At the end of each bin, the experimental program recorded whether a response had been made and an outcome occurred at the programmed probability. Using this procedure, Wasserman et al. (1993) examined ratings of multiple positive, negative, and zero contingency conditions and found that judgments were highly correlated with $\Delta P(r=.98)$. There was no evidence of judgments increasing with higher levels of OD. Therefore, judgments were highly accurate in tasks that according to Alloy and Tabachnik (1984) should have produced patterns of optimistic bias.

In summary, the contingency judgment experiments we have just described can be roughly categorized into three types: those that use a discrete trials procedure with an ITI, those that use a discrete trials procedure without an ITI, and those that use a free-operant procedure. Those studies in which an OD bias was observed (e.g., Alloy \& Abramson, 1979; Dickinson et al., 1984) used a discrete trials version of the tasks containing an ITI. However, OD bias is not observed when a discrete trials task with no ITI (Allan \& Jenkins, 1980) or a free-operant procedure is used (Wasserman et al., 1993). According to the expectations-based account, these three procedures should not affect the a priori expectations governing judgments because the scenarios are identical.

It could be argued that judgments in free-operant tasks are not susceptible to OD bias because responses and outcomes are more temporally contiguous. Learning is facilitated when there is a shorter delay between an event and its outcome (Shanks, Pearson, \& Dickinson, 1989). However, this aspect of task structure is not likely to be responsible for the different patterns of OD effects across tasks. For example, Allan and Jenkins (1980) found no evidence for OD effects using a discrete trials, operant procedure that involved weak temporal contiguity. However, in their study, trials were not separated by an ITI. Thus it would seem that the critical difference between experimental conditions that do elicit OD bias and those that do not is the presence or absence of an ITI.

This further suggests that the optimism of nondepressed people or, to put it more accurately, OD bias is not simply contingency and scenario dependent but also ITI dependent. It would seem that because the presence of OD bias in nondepressed people is the basis of the DR effect, exploring the underlying cause of OD bias and its ITI dependence might also elucidate the reasons as to why depressed people do not show the effect.

\section{The ITI Hypothesis and DR}

The ITI is a period of time in which the participant simply waits for the next trial and nothing happens. However, we propose that ITIs are also periods of time in which the participant is exposed to the experimental context in the absence of the occurrence of the outcome. In other words, ITIs could be conceptualized as no response-no outcome trials and as such are similar to events contained in Cell D of the contingency table. Cell D events happen when the response and the outcome do not occur in the experimental context. If ITIs were integrated into the contingency calculation as Cell D trials, this would be predicted to reduce the probability of outcome in the absence of the response. Consequently, integrating ITIs into the contingency calculation can produce radically different predictions of OD bias at both zero and positive levels of contingency (see also Baker, Murphy, ValleeTourangeau, \& Mehta, 2001).

The basis for this prediction can be explored with reference to the two zero contingency conditions where OD and DR effects are traditionally observed (see Figure 1). Recall that both conditions involved presenting the event-outcome conjunctions over 40 trials with 40 ITIs (including one at the end). The upper panel of Figure 1 shows how the contingency for both conditions is calculated in the usual manner and the lower panel shows the effect of adding 40 ITI or Cell D events. In both density conditions, adding to the $\mathrm{D}$ cell involves a reduction in the $P(\mathrm{O} / \mathrm{no} \mathrm{R})$, such that it is lower than the $P(\mathrm{O} / \mathrm{R})$. This leaves both contingencies as positive, with the high-density condition being more positive than the low-density condition. The absolute values of $\Delta P$ calculated with these modified cell frequencies would of course depend on how 

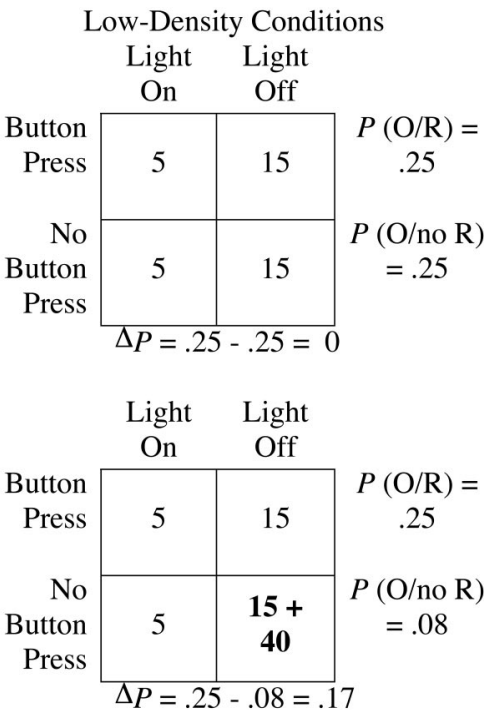
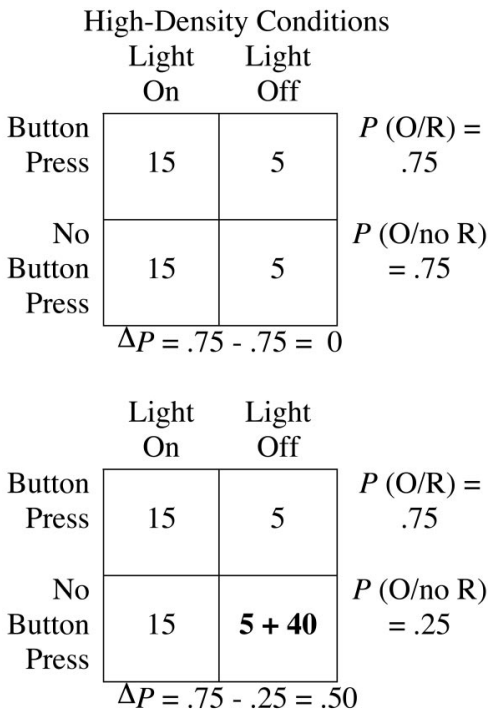

Figure 1. The effect of adding 40 intertrial intervals (ITIs) as D cells into low- and high-density zero contingency conditions. The upper panel shows the traditional $\Delta P$ calculations, and the lower panel shows how incorporating ITIs into the contingency table changes the $\Delta P$.

many D cells were added. However, any addition reduces the $P(\mathrm{O} /$ no $\mathrm{R})$, thereby increasing $\Delta P$. It may seem arbitrary to add exactly 40 extra Cell D events; however, any number added to this cell will have the same effect on the relative ordering of the contingencies. Thus, including ITIs in the contingency calculation produces predictions of OD effects.

The long ITI predictions are similar to the magnitude of judgments made by nondepressed people in the same conditions (Alloy \& Abramson, 1979). This suggests that when contingencies are judged in no-ITI situations, judgments are consistent with the programmed $\Delta P$ (e.g., Wasserman et al., 1993). However, when ITIs are used, the response-no outcome information is included, producing higher judgments of control with higher levels of OD. This accounts for the discrepancy in OD effects between judgments derived from procedures with different trial structures.

If nondepressed people's judgments fluctuate as a function of ITI length to produce OD effects, one implication is that depressed people's judgments are not influenced by this factor. The literature supports this argument because researchers running DR studies have used procedures containing particularly long ITIs. For example, Alloy and Abramson (1979) used a variable ITI with a mean length of $14 \mathrm{~s}$. In one study, which did not replicate the DR effect, relatively shorter ITIs of $2 \mathrm{~s}$ were used (e.g., Dobson \& Pusch, 1995). Our analysis suggests that whereas nondepressed people integrate ITIs into their perception of contingency, thereby increasing judgments of control, depressed people do so to a lesser extent. Given that such integration might be seen as normative, concepts of depressive performance as realistic may well need to be reassessed.

However, is there any other reason to suppose this might be the case, apart from the analysis that we have advanced? Depressive symptomatology includes not only affective aspects but also cognitive features, such as attention and concentration difficulties (American Psychiatric Association, 1994). Extended waiting periods occurring during the ITI might induce difficulties in maintain- ing attention, such that context information is not processed adequately. This would be less problematic during the experimental trials because the participant must perform an action and observe the outcome, and thus attention would be more focused. A related possibility involves the fact that depressed people have a tendency to engage in self- and symptom-focused ruminative thought (Nolen-Hoeksema, 1991). It has been found that high levels of rumination are associated with impaired concentration and attention, caused by a tendency for thoughts to wander and drift. This was evidenced by poor reading and reading comprehension as well as poor lecture comprehension performance in dysphorics induced to ruminate (Lyubomirsky, Kasri, \& Zehm, 2003). This evidence suggests that people who are not clinically depressed, such as the depressed participants in Alloy and Abramson's (1979) study, might have difficulty maintaining their attention through ITI periods and thus process this information differently than nondepressed people would. Although evidence currently available supports our analysis, no studies have directly tested our interpretation of the DR effect. We present two experiments systematically testing the effect of varying ITI length on OD bias and the DR effect.

\section{Experiment 1}

The first experiment was designed to test our prediction that varying the length of the ITI in a discrete trials procedure would substantially influence judgments in a high-density zero contingency condition. Furthermore, we predicted that this manipulation would influence nondepressed participants but not depressed participants. Participants were presented with contingency problems, modeled on the original Alloy and Abramson (1979) task, in which they judged the extent to which their pressing of a button controlled the onset of a light. To examine whether any difference in judgments attributable to ITI length was a function of the temporal 
contiguity between response and outcome, we also collected reaction time data.

\section{Method}

Participants. University students were recruited for this experiment using a mass screening method. All volunteers were required to complete the BDI (Beck et al., 1961) before being invited to participate. The resulting sample $(N=128)$ was selected on the basis of volunteers' BDI scores, with the constraint that there should be equal numbers of depressed and nondepressed male and female participants. Participants completed the BDI again during the experiment and, as in Alloy and Abramson (1979), were assigned to the depressed group (scores of 9 or above, $n=64$ ) or the nondepressed group (scores of 8 or below, $n=64$ ). Participants were then pseudo-randomly assigned to the four experimental conditions, with the constraint that there should be equal numbers of male and female participants in each group. As the procedure was not fully randomizeddepressive status is a nonrandom factor-the groups were matched on potential confounds such as working memory capacity, IQ, age, and levels of educational achievement, which could have contributed to any betweengroups effects. Working memory capacity was measured using the digit span test (forward version; Lezak, 1995), and IQ was measured using the National Adult Reading Test (NART; Nelson, 1982). The NART provides a well-validated estimate of IQ and is commonly used as an estimate of premorbid IQ in control and psychiatric populations (Crawford, Deary, Starr, \& Whalley, 2001). These data were analyzed with a factorial analysis of variance (ANOVA) including all the experimental conditions described below. The nondepressed groups $(M=4.20, S E=0.32)$ had significantly lower BDI scores than did the depressed groups $(M=15.00, S E=0.84)$, $F(1,112)=151.62, p<.001, M S E=24.60$. There was significant variability between the experimental groups on years of education, $F(1$, $112)=11.18, p=.001, M S E=4.48$; digit span, $F(1,112)=4.82, p=$ $.03, M S E=1.56$; and NART scores, $F(1,112)=5.38, p=.022, M S E=$ 34.18. Therefore, these factors were included in subsequent data analyses as covariates.

Design. In this experiment, we used a 2 (mood) $\times 2$ (ITI length) $\times 2$ (possibility of outcome) $\times 2$ (sex) fully factorial between-subjects design. A computerized version of the contingency judgment task used by Alloy and Abramson (1979) was used. Participants were asked to judge the extent of their control over light onset on a scale from 0 to 100 , where $0=n o$ control and $100=$ total control. Intermediate values represented varying degrees of partial control. The task was a high-density zero contingency condition $(.75 / .75)$. The experimental conditions differed as to whether the ITI was short ( $3 \mathrm{~s})$ or long $(15 \mathrm{~s})$ and whether the participants' mood was depressed or not depressed. Given that Alloy and Abramson (1979) found that the DR effect was stronger in women than in men, sex was included as a factor in all analyses to ensure that it did not moderate ITI effects. In the original DR experiments, presentation of stimuli was not computerized, thus the lightbulb was visible to participants during the ITI. In computerized contingency judgment procedures, the computer screen is usually blank during the ITI. Thus, for generality, we also manipulated whether the ITI was marked by the presence of the lightbulb (outcome possible) or a blank screen (outcome not possible). The effect of ITI length might also be confounded by the speed with which participants respond during the allowed interval. Therefore, reaction time data were collected to discount the possibility.

Apparatus. Presentation of experimental events was programmed using a Macintosh computer and REALbasic (Version 3) software.

Procedure. Participants were briefed verbally as to the nature of the experiment and given a written information sheet to read. After giving informed consent, participants completed the digit span test, the NART, and the BDI. Participants were then given instructions, displayed on the computer screen, on the task requirements. They were asked to judge how much control their pressing of a button had over a light switching on. They were further instructed upon the necessity of pressing the button on some occasions but not pressing the button on an approximately equal number of occasions. The task was presented on a computer screen, and each trial was constructed such that there was a 3-s opportunity for the participants to make their response by pressing the space bar. This period was signaled by an on-screen message saying, "You may press the button now!" This was followed by a 2-s period in which the lightbulb graphic either switched on or remained off. Each trial was followed by an ITI period, during which the unlit lightbulb either remained on the screen (outcome-possible condition) or the screen went blank (outcome-not-possible condition). The probability of light onset, both when the button was pressed and when the button was not pressed, was .75. Judgments were made after the 40 experimental trials had been completed. Participants were then debriefed.

\section{Results and Discussion}

Both the judgments of control and the reaction time data were analyzed using a between-subjects ANOVA with mood (nondepressed, depressed), ITI (short, long), possibility of outcome (possible, not possible), and sex (female, male) as between-subjects factors. Years of education, digit span, and NART scores were included in both analyses as covariates. An alpha level of .05 was used in all statistical tests except in unplanned comparisons where the alpha level was adjusted using the Bonferroni correction procedure ( $\alpha=.05 /$ number of comparisons).

Judgments of control. Nondepressed participants appeared to make higher judgments in the long ITI than in the short ITI conditions, whereas depressed participants did not (see Figure 2). Signaling the ITI with either a blank screen (outcome not possible) or the lightbulb remaining on the screen (outcome possible) appeared to have no effect on judgments, so we chose not to display the data by this factor.

The analysis confirmed these observations. Although none of the main effects were reliable (all $p \mathrm{~s}>.29$, all $\eta^{2} \mathrm{~s}<.01$ ), the interaction between mood and ITI length did suggest that the two mood groups responded differently to the ITI manipulation, $F(1$, 109) $=7.30, p=.008, \eta^{2}=.06, M S E=936.48$. Although the nondepressed people's judgments were influenced by the ITI manipulation, the depressed people's judgments were not. Two planned comparisons support this assertion. Nondepressed participants' judgments of control were significantly higher in the long than in the short ITI conditions, $F(1,109)=7.97, p=.006, \eta^{2}=$ $.03, M S E=936.48$, whereas depressed participants' judgments did not differ across the two ITI conditions, $F(1,109)=1.85, p=$ $.178, \eta^{2}=.006, M S E=936.48$. We also conducted two further post hoc comparisons with an alpha level adjusted to .025 . Both comparisons just failed to reach this conservative criterion. When the ITI length was short, depressed participants appeared to make higher judgments than nondepressed participants did, $F(1,109)=$ 5.18, $p=.025, \eta^{2}=.02, M S E=936.48$, and in long ITI conditions, nondepressed people's judgments were not significantly higher than depressed people's judgments, $F(1,109)=$ 3.63, $p=.059, \eta^{2}=.01, M S E=936.48$. The ITI $\times$ Mood interaction was not related to the effect of sex, $F(1,109)=1.75$, $p=.188, \eta^{2}=.02, M S E=936.48$, or the possibility of outcome occurrence ( $\left.p=.74, \eta^{2}=.001\right)$, and the four-way interaction was not significant $\left(p=.96, \eta^{2}<.001\right)$. This pattern of findings indicates that the interaction between mood and ITI length is caused by the increase in nondepressed people's judgments of control with longer ITIs, whereas depressed people's judgments were not influenced by this factor. 


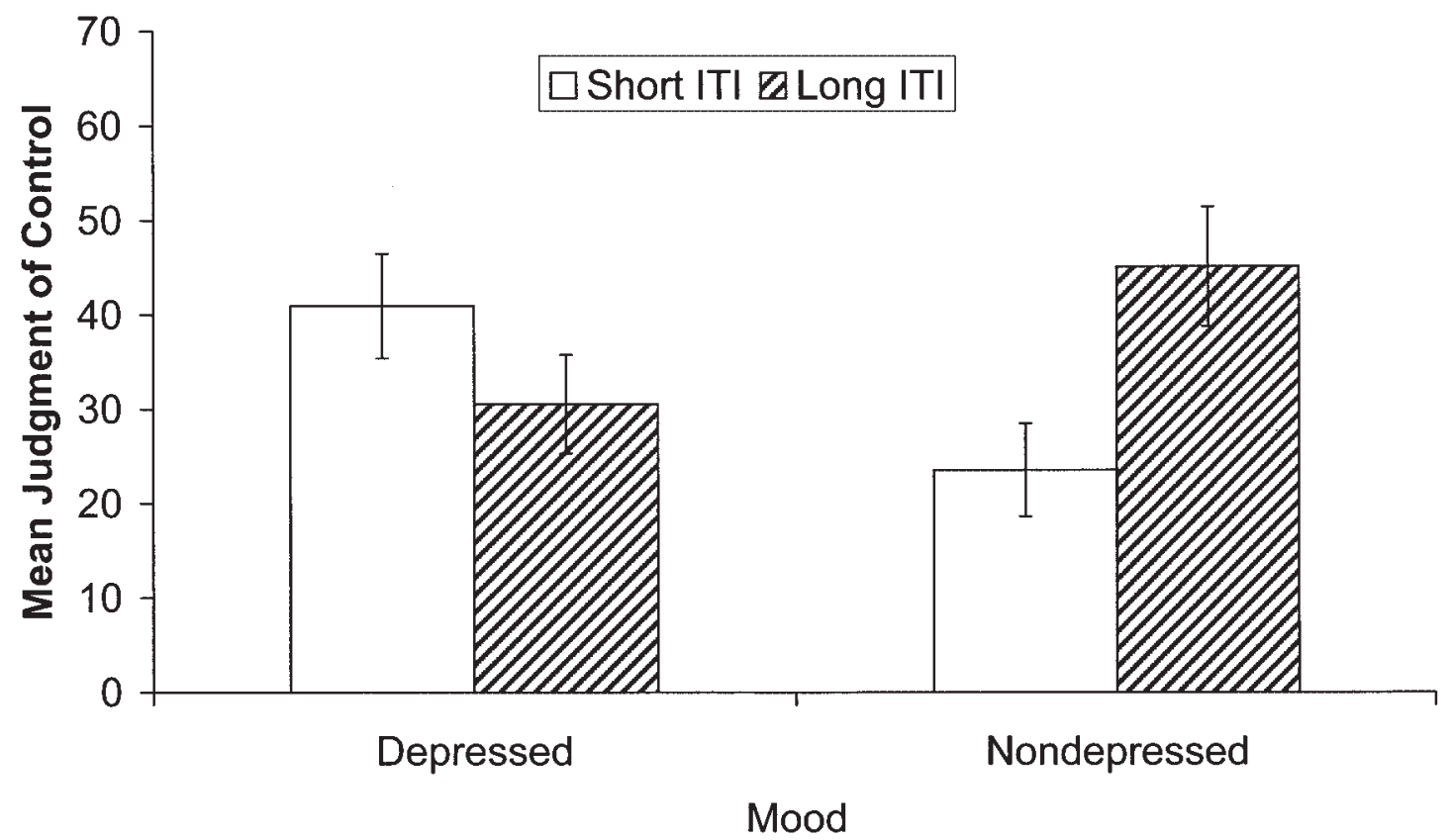

Figure 2. Mean judgments of control in a high-density zero contingency condition as a function of mood and length of intertrial interval (ITI). Error bars correspond to the standard error of the mean.

Reaction time data. An average response time (in milliseconds) was calculated for each participant; however, the data for 2 participants were lost due to computer malfunction. The analysis showed that ITI length did not influence reaction times, $F(1$, $107)=0.43, p=.51, \eta^{2}=.004, M S E=79,193.23$. None of the other main effects (all $p \mathrm{~s}>.34$, all $\eta^{2} \mathrm{~s}<.008$ ) or interactions were reliable except the effect of the possibility of the outcome, $F(1,107)=13.16, p<.001, \eta^{2}=.11, M S E=79,193.23$. Participants pressed the button faster $(M=974.96 \mathrm{~ms}, S E=$ 38.62) when the occurrence of the outcome was possible than when it was not possible $(M=1,160.84 \mathrm{~ms}, S E=32.44)$. This suggests that when the lightbulb remained on the screen during the ITI, participants maintained attention to the screen such that they could respond faster during the allowed interval.

Covariates. Years of education, digit span, and NART scores did not influence control judgments (all $p \mathrm{~s}>.15$, all $\eta^{2} \mathrm{~s}<.01$ ). Digit span and NART scores did not influence reaction time (all $p$ s $>.63$, all $\eta^{2} \mathrm{~s}=.002$ ). However, higher levels of education were related to longer reaction times, $F(1,107)=7.74, p=.006$, $\eta^{2}=.07, M S E=79,193.23$, where $\beta_{1}=24.32$. Because the covariate extracts this factor from the overall analysis, this finding will not be discussed further.

In summary, the results showed that nondepressed participants made higher judgments of control in a high-density zero contingency condition than depressed participants did. However, we found that this difference was influenced by the extent to which participants were exposed to a period of time in which nothing happened during the ITI. Nondepressed people's judgments in the long ITI condition were higher than short ITI judgments in the same condition, where the experimental trials contained an identical programmed contingency. One possible explanation for the difference may have to do with the speed with which participants made a response. Responding faster reduces the temporal contiguity between the response and the outcome, which in turn might have reduced the perception of contingency between responding and outcome. However, there was no evidence for this, as there was no relationship between reaction time and mood state or ITI.

The findings of Experiment 1 support our hypothesis that nondepressed people integrate ITIs into their judgments whereas depressed people do not. We proposed an analysis of this effect where ITIs might be perceived as no response-no outcome trials for the contingency calculation. The increase in nondepressed people's judgments of control in long ITI conditions is certainly consistent with the hypothesis that the length of the ITI has some effect on producing OD bias. However, it is also quite possible that longer ITIs might produce higher judgments in general. Because only a high-density condition was used in Experiment 1, this evidence might not be seen as sufficient to confirm the role of the ITI in OD bias. Therefore, a further experiment was carried out to extend and replicate the novel findings of Experiment 1, in which both high- and low-density zero contingency conditions were tested. Also, given that participants might have strong a priori expectations regarding the efficacy of responding with regard to light onset, the task scenario was adjusted to reduce such expectations.

\section{Experiment 2}

\section{Method}

Participants. Participants were recruited in the same manner as in the previous experiment and were assigned to depressed $(n=48)$ and nondepressed $(n=48)$ groups on the same basis as were participants in Experiment 1. As in Experiment 1, control data were collected from each participant. This was analyzed with a factorial ANOVA including the same 
factors as described in the Design section. Groups were successfully matched on sex, digit span, and age, but there was significant variability between groups on NART scores, $F(1,80)=4.41, p=.04, M S E=46.38$, and years of education, $F(1,80)=5.25, p=.025, M S E=4.83$. Therefore, subsequent data analysis included these factors as covariates. BDI scores were higher in the depressed groups $(M=16.52, S E=.32)$ than in the nondepressed groups $(M=4.19, S E=.34), F(1,80)=129.37, p<.001$, $M S E=28.19$.

Design. In this experiment, we used a 2 (mood) $\times 2$ (ITI length) $\times 2$ $(\mathrm{OD}) \times 2$ (sex) fully factorial between-subjects design. The judgment task was the same as that used in Experiment 1, but now participants could be judging either a high-density zero contingency $(.75 / .75)$ or a low-density zero contingency $(.25 / .25)$.

Procedure. The procedure was similar to that outlined in Experiment 1 except that the lightbulb was always present on the screen during the ITI. A modification was made to the instructions to reduce any influence of positive prior expectancies regarding light switches and light onset. Participants were asked to imagine that they were scientists who were testing a piece of equipment to be used in an experiment. The equipment comprised a lightbulb wired up to a light switch and a power supply. They were further told that this equipment was rather old and there were some doubts as to its reliability. This instruction was designed to minimize expectations regarding response efficacy.

\section{Results and Discussion}

The judgments of control and reaction time data were analyzed using a between-subjects ANOVA with mood (nondepressed, depressed), ITI (short, long), OD (low, high), and sex (female, male) as between-subjects factors.

Judgments of control. Participants' mean judgments in all experimental conditions are shown in Figure 3. The data suggest that there was no effect of ITI in low-OD conditions in either mood group. In high-OD conditions, nondepressed participants made higher judgments of control in the long ITI condition than in the short ITI condition. Their judgments were also higher than the depressed group's judgments in the long ITI, high-OD condition, which is evidence for the DR effect.

The ANOVA source table is displayed in Table 2. The predicted three-way interaction between ITI, OD, and mood was significant. Further analysis of the three-way interaction showed that in low-OD conditions, there were no reliable mood or ITI effects or a Mood $\times$ ITI interaction (all $p$ s $>.22$, all $\eta^{2} s<.005$ ). In high-OD conditions, however, the Mood $\times$ ITI interaction was significant, $F(1,78)=12.69, p<.001, \eta^{2}=.04, M S E=445.87$. Two further planned comparisons showed that although nondepressed participants' judgments of control were higher in the long than in the short ITI, high-OD condition, $F(1,78)=12.96, p<$ $.001, \eta^{2}=.04, M S E=445.87$, depressed participants' judgments did not change with ITI length, $F(1,78)=3.53, p=.06, \eta^{2}=.01$, $M S E=445.87$.

When ITIs were short, there were no effects of density or mood and no OD $\times$ Mood interaction (all $p \mathrm{~s}>.37$, all $\eta^{2} \mathrm{~s}<.003$ ), showing that neither mood group exhibited OD effects in short ITI conditions. However, when ITIs were long, the Mood $\times$ OD interaction was significant, $F(1,78)=4.46, p=.038, \eta^{2}=.02$, $M S E=445.87$. To interpret this interaction, we carried out four further unplanned comparisons with an alpha level of .0125 adjusted using the same procedure as was used in Experiment 1. Further analysis of the OD effect in the long ITI condition revealed that whereas nondepressed people made significantly higher judgments of control in the high-OD condition than in the low-OD condition, $F(1,78)=13.20, p=.005, \eta^{2}=.05, M S E=445.87$, depressed people did not $\left(p=.55, \eta^{2}=.001\right)$. We compared judgments in the two density conditions separately to examine mood effects. There was no difference between mood groups in the low-OD, long ITI condition $\left(p=.69, \eta^{2}<.001\right)$, but nondepressed people's judgments were significantly higher than de-

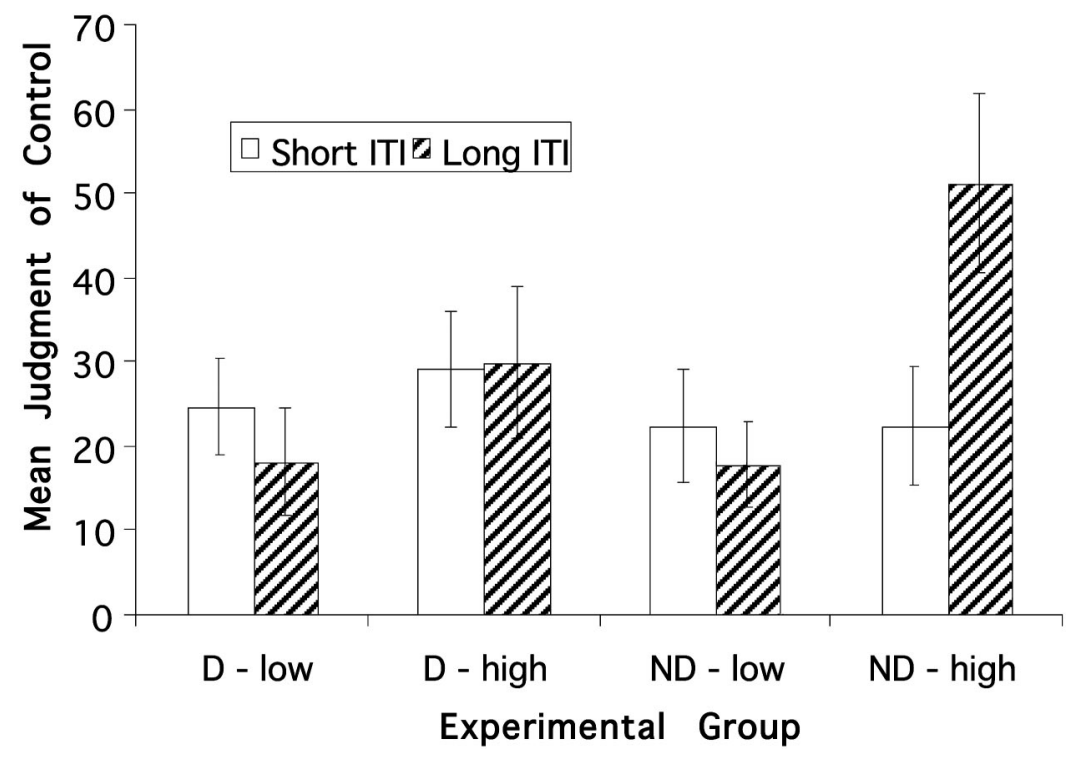

Figure 3. Mean judgments of control in a zero contingency condition as a function of intertrial interval (ITI) length, outcome density, and mood. Error bars correspond with the standard error of the mean. ND = nondepressed; D = depressed; low = low density; high = high density. 
Table 2

Analysis of Variance for the Judgment of Control Data in Experiment 2

\begin{tabular}{lcccc}
\hline \multicolumn{1}{c}{ Source } & $d f$ & $F$ & $\eta^{2}$ & $p$ \\
\hline NART & 1 & $14.01^{* * *}$ & .15 & $<.001$ \\
Education & 1 & 1.44 & .02 & .234 \\
Outcome density (OD) & 1 & $4.20^{*}$ & .05 & .044 \\
Mood & 1 & 1.85 & .02 & .178 \\
Sex & 1 & 0.49 & .02 & .487 \\
ITI & 1 & 0.02 & .00 & .881 \\
OD $\times$ Mood & 1 & 0.68 & .02 & .414 \\
OD $\times$ Sex & 1 & 0.48 & .01 & .491 \\
Mood $\times$ Sex & 1 & 3.68 & .05 & .059 \\
OD $\times$ Mood $\times$ Sex & 1 & $9.03^{* *}$ & .10 & .004 \\
OD $\times$ ITI & 1 & $5.26^{*}$ & .06 & .024 \\
Mood $\times$ ITI & 1 & $6.55^{*}$ & .08 & .012 \\
OD $\times$ Mood $\times$ ITI & 1 & $4.27^{*}$ & .05 & .042 \\
Sex $\times$ ITI & 1 & 0.02 & .00 & .879 \\
OD $\times$ Sex $\times$ ITI & 1 & 0.78 & .01 & .381 \\
Mood $\times$ Sex $\times$ ITI & 1 & 0.02 & .00 & .894 \\
OD $\times$ Mood $\times$ Sex $\times$ ITI & 1 & 3.50 & .04 & .065 \\
Within-group error & 78 & 445.87 & & \\
\hline
\end{tabular}

Note. $\quad$ NART $=$ National Adult Reading Test; ITI $=$ intertrial interval. $* p<.05 . \quad * * p<.01 . \quad * * * p<.001$.

pressed people's judgments in the high-OD, long ITI condition, $F(1,78)=11.60, p=.001, \eta^{2}=.04, M S E=445.87$.

Although ITI effects were not related to participants' sex, the fact that the four-way interaction approached the level of significance deserves some comment. This is most likely due to the finding that although as predicted, both male and female participants' judgments increased in a similar fashion as a function of ITI length in the important high-OD condition, this effect appeared to be stronger in male participants (see Table 3). However, this difference was not reliable because in the nondepressed participants' high-OD condition, the ITI effect was significant, $F(1$, $78)=12.96, p<.001, \eta^{2}=.04, M S E=445.87$, whereas both the effect of sex, $F(1,78)=3.18, p=.09, \eta^{2}=.01, M S E=445.87$, and the interaction between sex and ITI, $F(1,78)=2.28, p=.15$, $\eta^{2}=.007, M S E=445.87$, were not reliable. This pattern causes the nonsignificant four-way interaction. The overall analysis also shows that the OD $\times$ Mood $\times$ Sex interaction was reliable (see Table 2). This finding is not directly relevant to the subject of this article, but further discussion is presented in the Appendix.

Reaction time data. The mean reaction time for all participants was $1,066.15 \mathrm{~ms}(S E=29.58 \mathrm{~ms})$. There were no reliable effects of ITI length, $F(1,76)=3.30, p=.07, \eta^{2}=.04$; OD, $F(1,76)=$ $1.71, p=.19, \eta^{2}=.02 ;$ mood, $F(1,76)=1.43, p=.24, \eta^{2}=.02$; or $\operatorname{sex}\left(p=.36, \eta^{2}=.01\right)$, with $M S E=82,032.63$. None of the interactions reached the level of significance.

Covariates. NART scores and years of education were included as covariates in the overall ANOVAs conducted on the judgments of control and reaction time data. Neither factor influenced reaction times $\left(p s>.54, \eta^{2} \mathrm{~s}<.005\right)$, and NART scores were the only factor that significantly influenced judgments, $F(1$, $78)=14.02, p<.01, \eta^{2}=.15, M S E=445.87$. Higher NART scores (corresponding with higher IQ) were related to lower judgments of control $\left(\beta_{1}=-1.298\right)$. However, because the covariate extracts the influence of this factor from the analysis, this finding will not be discussed further.
In summary, the results of Experiment 2 showed that for nondepressed participants, the extent to which their judgments reflect OD bias depends on the length of the ITI. This was because judgments of high- and low-OD zero contingencies did not differ when the ITI was short. However, when the ITI was long, the high-OD condition received significantly higher judgments of control than the low-OD condition did. However, depressed people exhibited no evidence of OD bias in either the short or the long ITI conditions. Moreover, it was clear that DR was only evident with long ITI conditions. This indicates that the DR effect is not simply a function of mood and OD (e.g., Alloy \& Abramson, 1979) but is highly influenced by the length of the ITI.

\section{General Discussion}

Previous accounts of DR and normal optimism suggest that OD effects result from variations in expectations and motivation elicited by various scenarios and contingencies. Our findings show that OD effects in nondepressed people also result from additional contingency information derived from the ITI. There was no evidence that ITI effects were caused by changes in the temporal contiguity between response and outcome. This is consistent with evidence of no OD bias in procedures that do not contain an ITI (e.g., Allan \& Jenkins, 1980; Wasserman et al., 1993). Our findings also supported the hypothesis that depressed people do not exhibit OD bias because ITI length does not influence their judgments in the same manner. Overall, the results of this study provide preliminary supporting evidence for the role of ITI length in OD bias and DR. In the remainder of the discussion, we examine the relationship between our findings and theories of

Table 3

Mean Judgments of Control as a Function of Outcome Density, Mood, Sex, and Intertrial Interval (ITI) Length

\begin{tabular}{lccc}
\hline Mood and sex & ITI & $M$ & $S E$ \\
\hline & Low outcome density & & \\
Nondepressed & & & \\
Female & Short & 20.25 & 8.95 \\
Female & Long & 25.10 & 8.68 \\
Male & Short & 33.57 & 8.84 \\
Male & Long & 14.52 & 8.84 \\
Depressed & & & \\
Female & Short & 24.17 & 8.63 \\
Female & Long & 7.03 & 8.63 \\
Male & Short & 29.34 & 8.82 \\
Male & Long & 23.43 & 8.70 \\
\hline
\end{tabular}

High outcome density

\begin{tabular}{llrl} 
Nondepressed & & & \\
Female & Short & 15.56 & 8.80 \\
Female & Long & 34.90 & 8.63 \\
Male & Short & 24.86 & 8.66 \\
Male & Long & 68.44 & 8.64 \\
Depressed & & & \\
Female & Short & 40.55 & 8.64 \\
Female & Long & 33.53 & 8.24 \\
Male & Short & 22.41 & 8.73 \\
Male & Long & 9.13 & 9.59 \\
\hline
\end{tabular}


contingency judgment and depression and address the limitations of the present research.

\section{Relationship Between the ITI Hypothesis and Theories of Contingency Learning}

The ITI hypothesis allows the $\Delta P$ model to provide a straightforward account of OD effects in contingency learning. However, $\Delta P$ is generally seen as an inadequate model because it cannot explain other phenomena such as cue selection effects (for detailed discussions, see Allan, 1993; De Houwer \& Beckers, 2002; Shanks, 1993). Thus contemporary theorists have used associative models to describe the processes underlying contingency judgments (e.g., Dickinson et al., 1984) or developed computational descriptions in addition to $\Delta P$ (Cheng, 1997). The implications of the ITI hypothesis for these models are now discussed.

Associative models. A prototypical example of an associative model is the Rescorla-Wagner model (RWM; Rescorla \& Wagner, 1972). This model was originally designed to account for selective association phenomena in animal learning. The basic assumption of RWM is that associations develop between stimuli (i.e., the conditioned stimulus; $\mathrm{CS}$ ) and the outcome (i.e., the unconditioned stimulus; US) after repeated pairings. It is the strength of such associations that are thought to underpin conditioned behavior in animals but also contingency learning in humans (e.g., Dickinson et al., 1984). In addition to its assumptions about discrete stimuli, the RWM also assumes that the experimental context gains associative strength independently when presented with the outcome or loses it when presented alone. The context and the discrete events are predicted to compete for association because outcomes can only support a limited amount of associative power. It is this mechanism that allows the model to be sensitive to CS-US contingencies in animal and human learning (e.g., Murphy \& Baker, 2004; Rescorla, 1968).

When the contingency involves only one response and one outcome and all events are held to be equally salient, predictions derived from RWM are isomorphic with $\Delta P$; that is, at asymptote, the RWM equations equate to $\Delta P(\mathrm{G}$. B. Chapman \& Robbins, 1990). OD effects are therefore somewhat problematic for the RWM, although there have been some attempts to explain them. For example, if the events in the contingency table are held to be of unequal salience, then the model can predict OD effects. For example, the RWM contains learning rate parameters specifying the salience or effectiveness of the presence and the absence of the outcome. If the presence of the outcome is held to be more salient than its absence, the model produces predictions of negative OD effects. Low-OD conditions would then produce higher predicted levels of associative strength than would high-OD conditions (for details, see Wasserman et al., 1993). If, however, the occurrence of the outcome is considered to be less salient than its nonoccurrence, the RWM predicts positive OD effects (Shanks, Lopez, Darby, \& Dickinson, 1996). Yet the results of the current study show that the RWM does not require parameter manipulation to account for ITI effects or the varying patterns of OD effects across tasks with different trial structures.

This is because, similar to the way in which $\Delta P$ can incorporate ITIs as Cell D trials, the RWM can integrate ITIs as context-no outcome trials. Long periods of time when the context is present but the outcome does not occur could be predicted to reduce the context's association with the outcome, allowing the response to gain more associative strength in zero and positive contingency conditions (see Figure 4).

Figure 4 (left panel) shows how RWM predictions made for conditions without ITIs match those of $\Delta P$ in terms of the response-outcome relationship. In a zero contingency, the context gains more associative strength than the response, particularly in high-density conditions. The relationship between context and response is less clear in positive contingencies, where the context gains less strength than the response does in low-density conditions and the same amount of strength in high-density conditions. This pattern changes when ITIs are included in the model's predictions (see the right panel of Figure 4). In both zero and positive contingencies, the context gains little associative strength. This allows the response to acquire associative strength, particularly in high-density conditions where there are more event-outcome pairings. In fact, no matter how the parameters are set, incorporating ITIs into the model as context-no outcome trials produces predictions of OD effects, such that higher levels of OD will result in relatively more positive judgments.

Rule-based models. Although the RWM offers one theoretical framework for explaining the effects we have observed, it is not the only solution. Some researchers have suggested that people reason about cause-effect relationships by remembering all the events of the contingency table and calculating a statistic, similar to $\Delta P$, based on episodic memory (Cheng \& Novick, 1990). However, this theory has difficulty accounting for OD effects unless one assumes, like we have for the RWM, that extra ITIs are included in the calculation. More recently, Cheng (1997) has suggested that density effects reflect a secondary process related to causal reasoning and this is embodied in the power version of the probabilistic contrast model (PPC). In addition to $\Delta P$, Cheng has argued that causal reasoning involves the evaluation of the causal power between events. Power is driven by the intuition that for any cause of an effect, there are always potential alternative causes. Therefore, knowledge of the base rate of the effect (frequency of outcome) will enable one to make a contrast between the candidate cause and alternative causes such as the experimental context. Generative causal power is therefore defined not just by contingency but also by outcome contrasts. This can be reduced to the following equation:

$$
p_{i}=\frac{\Delta P}{1-P(e / \bar{i})},
$$

where $e$ is the occurrence of the outcome and $i$ is the occurrence of the event. When the putative cause is preventative, the denominator is simply $P(e / \bar{i})$. Therefore, the power for an event to cause an outcome is a joint function of the overall contingency $(\Delta P)$ and the probability of the outcome in the absence of the event. According to this model, higher levels of OD increase the base rate of the effect and reduce the denominator of the model, producing higher levels of causal power overall.

Although PPC is successful in predicting that higher levels of OD produce higher judgments of control in positive and negative contingency conditions (Cheng, 1997), it cannot predict OD bias in a zero contingency because the numerator of the equation is $\Delta P=$ 0 . In other words, power is always equal to zero. However, Cheng (1997) argued that participants misperceive a zero contingency as 


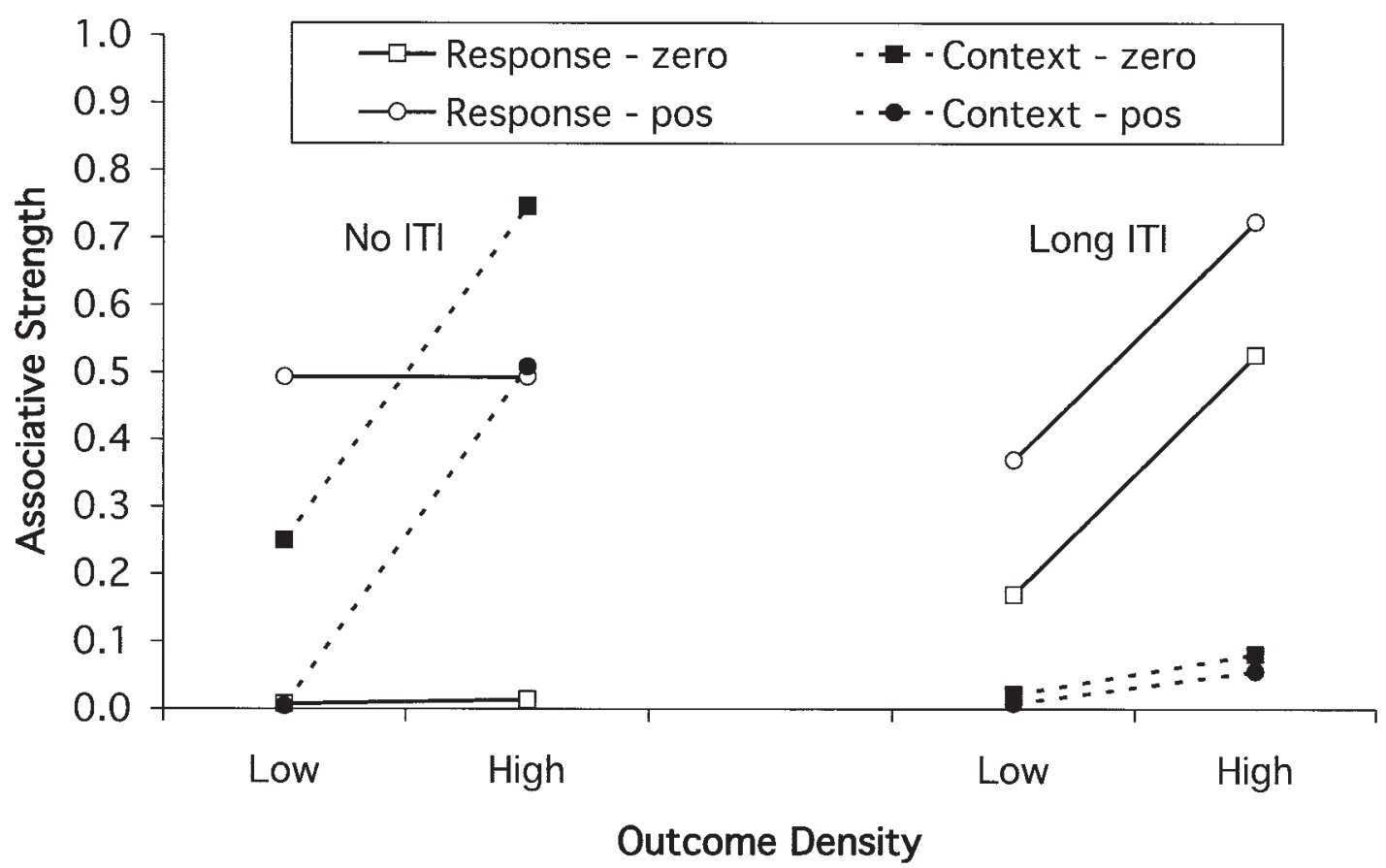

Figure 4. Asymptotic predictions of the Rescorla-Wagner model for conditions with no intertrial interval (ITI) and long ITIs, with zero and positive (pos) contingencies and conditions of low and high outcome density. The frequencies of events in zero contingency conditions are the same as those reported in Figure 1. The event frequencies in the positive contingency conditions were as follows (Cells A, B, C, D, respectively): low-density positive, 10, 10, 0, 20; high-density positive, 20, 0, 10, 10. ITIs were conceptualized as 40 context-no outcome trials, and the alpha level, $\beta 1$, and $\beta 0$ were all set to .02. Solid lines show the associative strength of the response and broken lines show the associative strength of the context.

either slightly positive or slightly negative, allowing the equation to predict OD bias. This might occur in the situation of a withinsubjects design, where participants judge multiple contingency problems and prior contingencies might produce proactive interference with subsequent contingencies (e.g., Baker, Berbrier, \& Vallee-Tourangeau, 1989). However, if within-subjects designs were the only source of misperception, OD bias should not be observed when using a between-subjects design. In the present experiments, and indeed in Alloy and Abramson's (1979) study, nondepressed participants only judged one contingency problem and still exhibited a strong OD bias. It can therefore be argued that OD bias in zero contingency conditions can only be accounted for with the additional assumption of a misperception of $\Delta P$. Our ITI hypothesis provides an empirically validated means by which a putative zero contingency might be misperceived. Therefore, both rule-based and associative models can predict that if ITIs are included in the perception of contingency, OD effects will occur at both zero and positive levels of contingency. However, the current findings do not allow one to decide which model provides a better account of contingency judgment.

The ITI hypothesis and positive contingencies. We have argued that DR effects occur because depressed people do not integrate ITIs into their judgments. One question that arises from this analysis, then, is why researchers have consistently failed to find evidence for DR effects in judgments derived from positive contingencies. Detecting DR effects requires testing in both high- and low-outcome densities of the same contingency, and we are not aware of such evidence with positive contingencies. Usually several different positive contingencies are compared. For example, Alloy and Abramson's (1979) experiment used three positive contingencies $(.75 / 0, .75 / .25$, and $.75 / .50$, where the $\Delta P$ s were .75 , .50 , and .25 , respectively). In addition, some contingencies are less influenced by changes in the D cell. For example, neither the RW nor the PPC models predict that differences in ITI integration would influence judgments of the $.75 / 0$ condition. Including extra $\mathrm{D}$ cells in the contingency calculation influences only the probability of the outcome in the absence of the response $P(\mathrm{O} / \mathrm{no} \mathrm{R})$, Therefore, if the frequency of Cell $\mathrm{C}$ is 0 , as in the positive .75 condition, this probability and the overall $\Delta P$ will not change. Finally, positive contingencies in general are less influenced by increases in the D cell. For example, adding extra D cell events to a high-density zero contingency with the following conditional probabilities, $P(\mathrm{O} / \mathrm{R})=1, P(\mathrm{O} /$ no $\mathrm{R})=1, \Delta P=1-1=0$, can theoretically drive the contingency toward a $\Delta P=1$, because the Cell $\mathrm{D}$ events will reduce the $P(\mathrm{O} /$ no $\mathrm{R})$ toward zero. This zero contingency could potentially vary between 0 and 1 with different ITI integration. A moderately positive high-density contingency, $P(\mathrm{O} / \mathrm{R})=1, P(\mathrm{O} /$ no $\mathrm{R})=5, \Delta P=1-.5=.5$, with extra $\mathrm{D}$ cells can also approach a value of $\Delta P=1$. The potential effect is to increase $\Delta P$ by only .5 . Therefore, the range of possible contingencies is smaller (.5 to 1 ) with positive contingencies compared 
with zero contingencies (0 to 1 ), and this may make them less sensitive to DR effects.

The ITI hypothesis and predictive contingencies. The evidence we have described in support of our ITI hypothesis pertains to operant contingency judgments. Is there any reason to suppose that ITIs might also be responsible for OD bias in predictive contingencies, where one passively experienced event predicts the occurrence of another event? One line of evidence would not support this contention. Allan and Jenkins $(1980,1983)$ used a discrete trials procedure where trials were not separated by an ITI. In three experiments examining operant zero contingencies, no OD effects were observed. However, in Allan and Jenkins's (1983) Experiment 3, participants passively observed an operant response occurring on the computer screen. This could therefore be regarded as a predictive contingency. In Allan and Jenkins's experiment, with the same trial structure as the other three experiments, judgments increased substantially with higher levels of OD. Similarly, Vallee-Tourangeau, Murphy, Drew, and Baker (1998) found large OD effects using a virus-disease prediction procedure with no ITI. This suggests that OD effects occur in operant contingencies for different reasons than why OD effects occur in predictive contingencies, because in operant contingencies, at least, we found OD effects to be restricted to long ITI conditions. This conclusion is consistent with findings that DR effects do not occur in predictive tasks (e.g., Alloy et al., 1985) or when predictive judgments are made about another person's control over an outcome (e.g., Martin et al., 1984). Therefore, it should be noted that the ITI hypothesis is so far restricted to operant contingencies.

\section{The Relationship Between the ITI Hypothesis and DR}

The current investigation has shown that the DR effect is not simply contingency dependent but ITI dependent. In a zero contingency condition, the ITI contains information that disconfirms the hypothesis that an individual does not control the occurrence of the outcome. The important question to answer is why depressed people do not integrate this information into their judgments.

A depressed individual in a zero contingency "self" control situation may make assumptions that influence his or her processing of the information concerning the alternative cause. In other words, he or she expects to have no control and pays little attention to ITI information that essentially disconfirms his or her hypothesis. However, fewer expectations and little experience in determining an "other's" control over events might result in a tendency to use expectations to arrive at a judgment. We argued in the introduction that self-esteem and negative expectations explanations for DR may be, on their own, inadequate. Nevertheless, when one combines these explanations with the ITI hypothesis regarding the relevance of alternative causes, a more complete explanation of the data emerges. Essentially, our account of the DR effect suggests that expectations and motivation influence the extent to which depressed people process and integrate information regarding potential alternative causes into their judgments. The advantage of this addition is that one can then explain why DR effects are limited to high-density zero contingencies, but this may change with task focus.

The idea that depressed people may to some extent ignore hypothesis-disconfirming information is not the only factor that might influence their integration of ITI information into judg- ments. Depressed people are known to spend considerable amounts of time ruminating about their feelings and the causes and consequences of their symptoms (Morrow \& Nolen-Hoeksema, 1990; Papageorgiou \& Wells, 2003). It could be argued that self-focused (e.g., control) tasks with long ITIs would leave depressed people particularly susceptible to experiencing a depressive ruminative response during the waiting periods. Thus depressed participants' attention would be focused on their ruminative thoughts as opposed to the subtle alternative cause or context information provided by the ITIs, producing the kind of effects we have observed. Although this explanation remains speculative, it certainly provides an interesting avenue for future research.

It is a widely held view that DR is inconsistent with theoretical descriptions and clinical observations of depressed cognition as being irrational and negatively biased (Alloy \& Abramson, 1988). We argue that the DR effect is not inconsistent with such descriptions. We have found that this is due to nondepressed people integrating all the available information into their judgment processes. This results in judgments that are actually more consistent with the overall level of contingency than those of depressed people are. Depressed people's judgments represent a consistent tendency to underestimate levels of contingency. Because depressed people's judgments do not change when the available background data change, it could be argued that this is a nonnormative tendency and thus unrealistic. Yet the more conservative conclusion might be that both are realistic and that neither is more correct, given the ambiguity of the ITI.

\section{Conclusions}

The clinically oriented approach to depressive cognition suggests that depressed individuals have low expectations of control and consequently make more accurate judgments than nondepressed individuals do about control in any situation where the contingency is low or zero. This line of reasoning has been undermined by numerous studies where the DR effect only occurs at certain ODs (e.g., Alloy \& Abramson, 1979; Benassi \& Mahler, 1985; Vasquez, 1987). Our findings on the lack of DR effects for short ITIs and low ODs add to this body of evidence. By contrast, our approach predicts different sizes of DR effects that are dependent on the OD and exposure to the ITI. Furthermore, these predictions fit well with clinical results and theories showing that depression influences cognitive activity and the ability to maintain attention, even in nonclinical populations (e.g., Farrin, Hull, Unwin, Wykes, \& David, 2003). The combination of a theoretical approach based on learning and experimental manipulations of ITIs thus have considerable potential for generating greater understanding of both normal and depressed thinking.

\section{References}

Ackermann, R., \& DeRubeis, R. J. (1991). Is depressive realism real? Clinical Psychology Review, 11, 565-584.

Allan, L. G. (1980). A note on measurement of contingency between two binary variables in judgment tasks. Bulletin of the Psychonomic Society, 15, 147-149.

Allan, L. G. (1993). Human contingency judgments: Rule-based or associative? Psychological Bulletin, 114, 435-448.

Allan, L. G., \& Jenkins, H. M. (1980). The judgment of contingency and 
the nature of the response alternatives. Canadian Journal of Psychology, $34,1-11$

Allan, L. G., \& Jenkins, H. M. (1983). The effect of representations of binary variables on judgment of influence. Learning and Motivation, 14, 381-405.

Alloy, L. B., \& Abramson, L. Y. (1979). Judgment of contingency in depressed and nondepressed students: Sadder but wiser? Journal of Experimental Psychology: General, 108, 441-485.

Alloy, L. B., \& Abramson, L. Y. (1988). Depressive realism: Four theoretical perspectives. In L. B. Alloy (Ed.), Cognitive processes in depression (pp. 223-265). New York: Guilford Press.

Alloy, L. B., Abramson, L. Y., \& Kossman, D. A. (1985). The judgement of predictability in depressed and nondepressed college students. In F. R. Brush \& J. B. Overmier (Eds.), Affect, conditioning, and cognition: Essays on the determinants of behavior (pp. 229-246). Hillsdale, NJ: Erlbaum.

Alloy, L. B., \& Tabachnik, N. (1984). Assessment of covariation by humans and animals: The joint influence of prior expectations and current situational information. Psychological Review, 91, 112-149.

American Psychiatric Association. (1994). Diagnostic and statistical manual of mental disorders (4th ed.). Washington, DC: Author.

Baker, A. G., Berbrier, M. W., \& Vallee-Tourangeau, F. (1989). Judgements of a $2 \times 2$ contingency table: Sequential processing and the learning curve. Quarterly Journal of Experimental Psychology: Comparative and Physiological Psychology, 41B, 65-97.

Baker, A. G., Murphy, R. A., Vallee-Tourangeau, F., \& Mehta, R. (2001). Contingency learning and causal reasoning. In R. R. Mowrer \& S. B. Klein (Eds.), Handbook of contemporary learning theories (pp. 255306). Mahwah, NJ: Erlbaum.

Beck, A. T. (1967). Depression: Clinical, experimental and theoretical aspects. London: Staples Press.

Beck, A. T., Ward, C. H., Mendelson, M., Mock, J., \& Erbaugh, J. (1961). An inventory for measuring depression. Archives of General Psychiatry, 4, 561-571.

Benassi, V. A., \& Mahler, H. I. M. (1985). Contingency judgments by depressed college students: Sadder but not always wiser. Journal of Personality and Social Psychology, 49, 1323-1329.

Carson, R. C. (2001). Depressive realism: Continuous monitoring of contingency judgements among depressed outpatients and non-depressed controls. Vanderbilt University, Nashville, TN.

Chapman, G. B., \& Robbins, S. J. (1990). Cue interaction in human contingency judgment. Memory \& Cognition, 18, 537-545.

Chapman, L. J., \& Chapman, J. P. (1967). Genesis of popular but erroneous psychodiagnostic observations. Journal of Abnormal Psychology, 72, 193-204.

Cheng, P. W. (1997). From covariation to causation: A causal power theory. Psychological Review, 104, 367-405.

Cheng, P. W., \& Novick, L. R. (1990). A probabilistic contrast model of causal induction. Journal of Personality and Social Psychology, 58, $545-567$.

Clark, D. A., Beck, A. T., \& Alford, B. A. (1999). Scientific foundations of cognitive theory and therapy of depression. New York: Wiley.

Cobbs, D. L., Critelli, J. W., \& Tang, C. S. (1990). Judgement of contingency in clinical depressives. Unpublished manuscript, University of North Texas, Denton.

Coyne, J. C., \& Gotlib, I. H. (1983). The role of cognition in depression: A critical appraisal. Psychological Bulletin, 94, 472-505.

Crawford, J. R., Deary, I. J., Starr, J., \& Whalley, L. J. (2001). The NART as an index of prior intellectual functioning: A retrospective validity study covering a 66-year interval. Psychological Medicine, 31, 451-458.

Crocker, J. (1981). Judgment of covariation by social perceivers. Psychological Bulletin, 90, 272-292.

De Houwer, J., \& Beckers, T. (2002). A review of recent developments in research and theories on human contingency learning. Quarterly Journal of Experimental Psychology: Comparative and Physiological Psychology, 55B(4), 289-310.

Dickinson, A., Shanks, D., \& Evenden, J. (1984). Judgement of actoutcome contingency: The role of selective attribution. Quarterly Journal of Experimental Psychology:-Human Experimental Psychology, 36 , 29-50.

Dobson, K., \& Franche, R.-L. (1989). A conceptual and empirical review of the depressive realism hypothesis. Canadian Journal of Behavioural Science, 21, 418-433.

Dobson, K., \& Pusch, D. (1995). A test of the depressive realism hypothesis in clinically depressed subjects. Cognitive Therapy and Research, 19, 179-194.

Ee, J. S. C. (1994). Judgment of contingency in hospitalized depressives. Unpublished doctoral dissertation, University of North Texas, Denton.

Farrin, L., Hull, L., Unwin, C., Wykes, T., \& David, A. (2003). Effects of depressed mood on objective and subjective measures of attention. Journal of Neuropsychiatry and Clinical Neurosciences, 15, 98-104.

Gotlib, I. H., Kurtzman, H. S., \& Blehar, M. C. (1997). Cognition and depression: Issues and future directions. Cognition \& Emotion, 11, 663-673.

Langer, E. J. (1975). The illusion of control. Journal of Personality and Social Psychology, 32, 65-84.

Lennox, S. S., Bedell, J. R., Abramson, L. Y., Raps, C., \& Foley, F. W. (1990). Judgment of contingency: A replication with hospitalized depressed, schizophrenic and normal samples. Journal of Social Behavior and Personality, 5(4), 189-204.

Lewinsohn, P. M., Mischel, W., Chaplin, W., \& Barton, R. (1980). Social competence and depression: The role of illusory self-perceptions? Journal of Abnormal Psychology, 89, 203-212.

Lezak, M. D. (1995). Neuropsychological assessment (3rd ed.). New York: Oxford University Press.

Lyubomirsky, S., Kasri, F., \& Zehm, K. (2003). Dysphoric rumination impairs concentration on academic tasks. Cognitive Therapy and Research, 27, 309-330.

Martin, D. J., Abramson, L. Y., \& Alloy, L. B. (1984). Illusion of control for self and others in depressed and nondepressed college students. Journal of Personality and Social Psychology, 46, 125-136.

Morrow, J., \& Nolen-Hoeksema, S. (1990). Effects of responses to depression on the remediation of depressive affect. Journal of Personality and Social Psychology, 58, 519-527.

Murphy, R. A., \& Baker, A. G. (2004). A role for CS-US contingency in Pavlovian conditioning. Journal of Experimental Psychology: Animal Behavior Processes, 30, 229-239.

Nelson, H. (1982). National adult reading test (NART): Test manual. Windsor, England: NFER-Nelson.

Nolen-Hoeksema, S. (1991). Responses to depression and their effects on the duration of depressive episodes. Journal of Abnormal Psychology, 100, 569-582.

Papageorgiou, C., \& Wells, A. (2003). An empirical test of a clinical metacognitive model of rumination and depression. Cognitive Therapy and Research, 27, 261-273.

Rescorla, R. A. (1968). Probability of shock in the presence and absence of the CS in fear conditioning. Journal of Comparative and Physiological Psychology, 66, 1-5.

Rescorla, R., \& Wagner, A. (1972). A theory of Pavlovian conditioning: Variations in the effectiveness of reinforcement and non-reinforcement. In A. H. Black \& W. F. Prokasy (Eds.), Classical conditioning II: Current research and theory (pp. 64-99). New York: AppletonCentury-Crofts.

Shanks, D. R. (1993). Human instrumental learning: A critical review of data and theory. British Journal of Psychology, 84, 319-354.

Shanks, D. R., Lopez, F. J., Darby, R. J., \& Dickinson, A. (1996). Distinguishing associative and probabilistic contrast theories of human contingency judgment. In D. R. Shanks, K. Holyoak, \& D. L. Medin 
(Eds.), Causal learning (Vol. 34, pp. 265-311). San Diego, CA: Academic Press.

Shanks, D., Pearson, S. M., \& Dickinson, A. (1989). Temporal contiguity and the judgment of causality by human subjects. Quarterly Journal of Experimental Psychology: Comparative and Physiological Psychology, $41,139-159$.

Smedslund, J. (1963). The concept of correlation in adults. Scandinavian Journal of Psychology, 4(3), 165-173.

Teasdale, J. D., \& Barnard, P. J. (1993). Affect, cognition and change: Remodelling depressive thought. Hillsdale, NJ: Erlbaum.

Vallee-Tourangeau, F., Murphy, R. A., Drew, S., \& Baker, A. G. (1998). Judging the importance of constant and variable candidate clauses: A test of the power PC theory. Quarterly Journal of Experimental Psychology: Human Experimental Psychology, 51, 65-84.
Vasquez, C. (1987). Judgment of contingency: Cognitive biases in depressed and nondepressed subjects. Journal of Personality and Social Psychology, 52, 419-431.

Wasserman, E. A., Chatlosh, D. L., \& Neunaber, D. J. (1983). Perception of causal relations in humans: Factors affecting judgments of responseoutcome contingencies under free-operant procedures. Learning and Motivation, 14, 406-432.

Wasserman, E. A., Elek, S. M., Chatlosh, D. L., \& Baker, A. G. (1993). Rating causal relations: Role of probability in judgments of responseoutcome contingency. Journal of Experimental Psychology: Learning, Memory, and Cognition, 19, 174-188.

Williams, J. M. G., Watts, F. N., MacLeod, C., \& Mathews, A. (1997). Cognitive psychology and emotional disorders (2nd ed.). Oxford, England: Wiley.

\section{Appendix}

\section{Analysis and Discussion of Sex Differences Found in Experiments 1 and 2}

In both experiments, we found sex effects that were distinct from the ITI effects that we report in the main article. The analysis of the judgment-ofcontrol data showed that the interaction between mood and sex was significant, $F(1,109)=5.22, p=.024, \eta^{2}=.05, M S E=936.48$. Four further unplanned comparisons were conducted with an alpha level adjusted to .0125 . Nondepressed male participants $(M=43.53, S E=6.34)$ made higher judgments of control than nondepressed female participants $\operatorname{did}(M=25.19, S E=5.42), F(1,109)=5.75, p=.018, \eta^{2}=.02, M S E=$ 936.48 (although this difference just failed to reach the adjusted significance level), but did not differ significantly from depressed male participants $(M=33.09, S E=4.89), F(1,109)=1.86, p=.175, \eta^{2}=.006$, $M S E=936.48$. There were no differences between the judgments of the depressed female $(M=38.44, S E=5.70)$ and male participants $(p=.51$, $\left.\eta^{2}=.002\right)$ and the depressed and nondepressed female participants, $F(1$, 109) $=2.99, p=.087, \eta^{2}=.01, M S E=936.48$.

In Experiment 2, we made a similar finding. The three-way interaction between OD, mood, and sex was reliable, $F(1,78)=9.03, p=.004, \eta^{2}=$ $.10, M S E=445.87$. Although the Density $\times$ Mood interaction was not reliable for female participants' judgments, $F(1,78)=2.47, p=.12, \eta^{2}=$ $.008, M S E=445.87$, it was significant for male participants' judgments, $F(1,78)=6.53, p=.013, \eta^{2}=.02, M S E=445.87$. The alpha level was adjusted to .025 for further comparisons. Although there was no mood difference in male participants' judgments in the low-density condition ( $p=.96)$, nondepressed male participants made significantly higher judgments of control than the depressed male participants did in the high-- density condition, $F(1,78)=10.80, p=.002, \eta^{2}=.04, M S E=445.87$. This replicates the findings of Experiment 1, which, taken together, suggest that irrespective of ITI, there is a more prominent illusion of control in nondepressed men.

This is in contrast to the findings of Alloy and Abramson (1979, Experiment 2), who found that the effect was stronger in female participants. Their explanation for this sex difference was based on Langer's (1975) work, which showed that task demands for rationality differentially influenced male and female participants. Men were found to be less susceptible to illusions of control in conditions where rationality was emphasized. Alloy and Abramson (1979) argued that their task instructions "strongly emphasized" (p. 462) rationality, which may have caused this sex difference. In the current experiment, we used a simplified version of their instructions, which may also have reduced the task rationality, producing the pattern of sex effects we observed. Indeed, Alloy and Abramson's Experiment 3, which de-emphasized task rationality, produced judgments in which men did show the illusion of control. This suggests that the sex effects observed in the current experiments may be consistent with previous findings and explanations for sex differences in contingency judgments.

Received January 8, 2004 Revision received August 25, 2004 Accepted September 9, 2004

\section{Online Preview of JEP: General Articles}

Are you an APA member or affiliate who subscribes to JEP: General? If so, you now have online access to the most recently accepted articles before they appear in print. Articles accepted and scheduled for publication are available on the journal's Web site at least 2 months prior to print publication. Access to this feature is available at no charge via

\section{http://www.apa.org/journals/xge.html}

to APA members and affiliates who subscribe to JEP: General. 